\title{
THE REFLECTION OF THE IDEAS OF ZIYA GYOKALP IN THE THEORY AND PRACTICE OF KEMALISM
}

\author{
Egnara G. Vartanyan \\ Kuban State Universaty, Krasnodar, Russian Federation
}

\begin{abstract}
Introduction. The article is devoted to reflecting the ideas of Turkish philosopher, sociologist, culture expert Ziya Gyokalp in the concepts of Kemalism, to the problem of reasonable mutual influence of the East and West, to the attempts of the first President of the Republic of Turkey Mustafa Kemal Atatyurk to introduce turkish society in the Westernized civilization in the 1920-1930s. The first Turkish president interpreted the ideas of Ziya Gyokalp, who fought for the synthesis of national traditions and European civilization achievements. The president defined such milestones in the political life of Turkey as europeanization, nationalism, laicism, etatism, revolutionism, nationality, republicanism. The article shows the struggle of westernists and traditionists; calls of nationalists to preserve national traditions, study the history of Muslim peoples and state institutions to make their adapting to new conditions of life in modernity easier. Only the balance between traditionalism and modernism can correspond to the realities of a particular society and era, while the westerners called for the transfer of European values to the national soil. Methods. The historical-typological and historical-system research methods used in the article allowed to analyze the typology and transformation of Turkish culture in the first two decades of the republic's existence. Analysis. The article shows the struggle of Westerners and Traditionalists, the appeals of nationalists to preserve national traditions, to study the history of Muslim peoples and state institutions in order to adapt them for modern life more easily, because only the relationship between traditionalism and modernism can correspond to the realities of a particular society and to the modern epoch, while Westerners wanted to bind European values and national soil. Results. The article draws the conclusion that fundamental principles of Kemalism were formulated by M.K. Atatyurk and implemented by him and his supporters not immediately, but step by step, beginning with 1918. The ideology of Kemalism is in tune with the ideas of Ziya Gyokalp to a great extent. The paper emphasizes that during the decades since the first attempts to modernize Turkey the state has taken unprecedented steps to import Western culture. Undoubtedly, transformations in Turkish society in the field of government, culture, and everyday life were of progressive importance. It contributed to national strengthening of Turkey and its transition from feudal to bourgeois forms of social life.
\end{abstract}

Key words: Turkey, westernisation, traditionalism, islamizm, kemalizm, laicism, modernization.

Citation. Vartanyan E.G. The Reflection of the Ideas of Ziya Gyokalp in the Theory and Practice of Kemalism. Vestnik Volgogradskogo gosudarstvennogo universiteta. Seriya 4. Istoriya. Regionovedenie. Mezhdunarodnye otnosheniya [Science Journal of Volgograd State University. History. Area Studies. International Relations], 2019, vol. 24, no. 3, pp. 137-146. (in Russian). DOI: https://doi.org/10.15688/jvolsu4.2019.3.12

УДК 94(560“1918/...”:316.75

ББК 63.3(5Туц)6-72

Дата поступления статьи: 03.02.2018

Дата принятия статьи: 21.06.2018

\section{ОТРАЖЕНИЕ ИДЕЙ ЗИИ ГЁКАЛПА В ТЕОРИИ И ПРАКТИКЕ КЕМАЛИЗМА}

Кубанский государственный университет, г. Краснодар, Российская Федерация

Аннотация. Введение. Статья посвящена вопросу отражения идей турецкого философа, социолога, культуролога Зии Гёкалпа в концепциях кемализма, проблеме разумного взаимовлияния Востока и Запада, попыткам первого президента Турецкой Республики Мустафы Кемаля Ататюрка ввести в 1920-1930-е гг. турецкое общество в вестернизированную цивилизацию. Интерпретируя идеи Зии Гёкалпа, ратовавшего за 
синтез национальных традиций и достижений европейской цивилизации, первый турецкий президент определил такие вехи в политической жизни Турции, как европеизация, национализм, лаицизм, этатизм, революционность, народность, республиканизм. Meтоды. Использованные в статье историко-типологический, историко-системный методы и цивилизационный подход позволили проанализировать типологию и трансформацию турецкой культуры в первые два десятилетия существования республики. Анализ. В статье показана борьба вестернистов и традиционалистов, отмечены призывы почвенников к сохранению национальных традиций, изучению истории мусульманских народов и государственных институтов для того, чтобы легче приспособить их к новым условиям жизни в современности, ибо только соотношение между традиционализмом и модернизмом может соответствовать реалиям конкретного общества и эпохи, тогда как западники призывали перенести на национальную почву европейские ценности. Результаты. Делается вывод о том, что основополагающие принципы кемализма были сформулированы М.К. Ататюрком и реализованы им и его сторонниками не сразу, а по этапам, начиная с 1918 года. В немалой степени идеология кемализма созвучна идеям Зии Гёкалпа. Подчеркивается, что за десятки лет, прошедших с первых попыток модернизации Турции, государство предприняло беспрецедентные шаги по импорту западной культуры. Несомненно, преобразования в турецком обществе в области государственного устройства, культуры, быта имели прогрессивное значение. Они способствовали национальному укреплению Турции и ее переходу от феодальных к буржуазным формам общественной жизни.

Ключевые слова: Турция, вестернизация, традиционализм, исламизм, кемализм, лаицизм, модернизация.

Цитирование. Вартаньян Э. Г. Отражение идей Зии Гёкалпа в теории и практике кемализма // Вестник Волгоградского государственного университета. Серия 4, История. Регионоведение. Международные отношения. - 2019. - Т. 24, № 3. - С. 137-146. - DOI: https://doi.org/10.15688/jvolsu4.2019.3.12

Введение. Одна из закономерностей развития мира - ее биполярность, наличие различных культурных полюсов, одновременно противостоящих и взаимодополняющих друг друга. Это относится в первую очередь к странам Востока и Запада, их вечному противопоставлению. В современных условиях необходимо такое научно-историческое понимание развития общества, которое утверждает цивилизованный подход, основанный на признании уважения ко всяким культурам и конфессиям, отказ как от европоцентризма, так и от азиацентризма. В данном контексте интересна проблема соотношения традиционализма и вестернизма в Турции, стране, которая географически находится между двумя частями света - Европой и Азией, образуя линию, разделяющую Европу и Ближний Восток. Геостратегическое положение Турции превращает страну в своеобразный мост между Востоком и Западом. Турция действительно является частью двух регионов Запада и Востока, поэтому на нее влияют события, происходящие в обоих регионах, тем более с учетом их исторических и культурных связей.

С момента создания республики в 1923 г. политика Турции имела два основных аспекта внешнеполитического развития: установление прочных связей с Западом и мирных отношений со странами Ближнего Востока.
Выяснить, как происходило взаимодействие Запада и Востока в период формирования Турецкой Республики на институциональном уровне и как соотносились идеи первого президента Турецкой Республики Мустафы Кемаля Ататюрка с идеями, заложенными в трудах турецкого философа, социолога, культуролога Зии Гёкалпа, - основная задача, которую ставит перед собой автор данной статьи.

Meтоды. Использованные в исследовании историко-типологический, историкосистемный методы и цивилизационный подход позволили проанализировать типологию и трансформацию турецкой культуры в республиканский период. Автор попытался выявить социально-экономический, политический и историко-культурный тип Турецкой Республики с начала ее существования на основе веберовского метода теоретической типологии. Кроме того, был проведен анализ турецкого общества на основе характеристики его системного развития в соответствии с историко-системным методом познания И.Д. Ковальченко. На основе трудов А. Тойнби, К. Ясперса, О. Шпенглера, Н.Я. Данилевского, С. Хантингтона использован цивилизационный подход к рассмотрению соотношения идеологии кемализма и идей Зии Гёкалпа. Цивилизационный подход позволил выявить многообразие и вариативность фор- 
мирования и развития общества вообще и турецкого в частности.

Анализ. Во второй половине XIX - начале $\mathrm{XX}$ в. в османо-турецком обществе начинается поиск альтернативных концепций развития государства, что было, в немалой степени, следствием кризиса традиционной идентичности. В результате во второй половине XIX в. стали появляться новые для османского общества школы политической мысли, которые в дальнейшем оказали решающую роль на формирование идеологии кемализма. Школа «вестернистов» (западники) выступала за перенос на национальную почву западных ценностей, освоение османским обществом европейского образа жизни, радикальные общественные преобразования и трансформацию Турции в современное просвещенное государство. Представителями вестернистов в Турции были Тевфик Фикрет, Абдуллах Джевдет, Намык Кемаль и ряд политических и культурных деятелей XIX - начала XX века. $\mathrm{B}$ течение многих десятилетий вопрос о совместимости ислама и европейской цивилизации был острейшей проблемой для турок и других мусульманских народов. В младотурецкой партии «Единение и прогресс» и на страницах «вольной» прессы в конце XIX начале XX в. происходили дискуссии по вопросу о совместимости мусульманской и европейской цивилизаций. Термин «вестернизация» применительно к ряду азиатских стран широко используется уже много десятилетий, поскольку вестернизация характерна для многих развивающихся стран. Однако протекает этот процесс по-разному. В ряде случаев преобразования происходят настолько стремительно и приобретают такой форсированный характер, что основная масса населения не в состоянии понять и принять навязываемые правительством новации. В результате наблюдается откат общества к своим истокам, национальным ценностям.

Вторым идеологическим течением Османской империи был национализм, который возник как реакция турок на национализм других этнических групп империи. В начале $\mathrm{XX}$ в. турецкий национализм перешел в политическую фазу развития, когда теоретические разработки трансформировались в идеологические конструкции [2, с. 166]. Видным предста- вителем идеологии турецкого национализма был Ю. Акчура, взгляды которого легли в основу концепции пантюркизма. Наиболее сильное влияние на идеологию кемализма оказал основоположник доктрины тюркизма, турецкий философ, социолог, культуролог Зия Гёкалп (1876-1924), который изложил свою концепцию в работах «Основы тюркизма», «Турецкий национализм и Западная цивилизация» [16] и др. Тюркизм он определил как светское националистическое движение, целью которого является обновление и культурный подъем общества [12, с. 65$]$.

Формирование личности Зии Гёкалпа на раннем этапе происходило под влиянием идей известных деятелей движения «новых османов» и ярких представителей турецкой культуры эпохи танзимата (1839-1876 гг.) Намыка Кемаля и Ибрагима Шинаси. Уже в конце XIX в. Зия Гёкалп увлекся идеями тюркизма и стал одним из идеологов младотурецкого движения. Активная интеллектуальная деятельность тюркистов и вестернистов оказала значительное влияние на режим младотурок, пришедших к власти после революции 19081909 гг. и управлявших страной до распада Османской империи в 1918 году. Несмотря на то что лидеры младотурок отдавали предпочтение идеологиям османизма, исламизма и пантюркизма, они инициировали в стране ряд светских преобразований, которые могут рассматриваться как прелюдия к реформам Ататюрка [2, с. 168].

В период Первой мировой войны Зия Гёкалп в основном занимался разработкой концепции турецкого национализма [16]. Философ считал, что турецкому обществу недостает осознания ценности исторической традиции, в то же время происходят формальные заимствования европейской цивилизации, что лишает общество созидательности и будущего. В ходе Балканских войн (1912-1913 гг.), по мнению Зии Гёкалпа, болгары вдохновлялись собственными традициями, турки - холодными призывами своих правителей, в результате - победа «истории над географией» [12, c. 43]. Таким образом, считает Зия Гёкалп, туркам нужно знать национальные традиции, собственную историю, историю мусульманских народов, государственных институтов для того, чтобы легче приспособить их к новым 
условиям жизни в современности, ибо только соотношение между традиционализмом и модернизмом может соответствовать реалиями конкретного общества и эпохи.

Зия Гёкалп допускал возможность совместимости христианского и исламского начал, одним из первых среди мусульманских философов понял необходимость разделения институтов религиозных (шариатских) и государственных, говорил о секуляризации разных сфер социально-экономической, политической и духовной жизни. На основе анализа опыта европейских государств он пришел к выводу, что религия не проигрывает от институционального разделения сфер деятельности, а наоборот, начинает выполнять собственную функцию более глубоко. В этом случае он апеллирует к истории ислама в Индии, Египте, Китае, Индонезии, мусульманских регионов России, подчеркивая, что слияние религии с государством приводит тому, что ислам начинает терять свою жизнеспособность, превращается в формализованную правовую систему, закрытую от согласованного мнения членов религиозной общины - иджтихада [16, p. 103]. Зия Гёкалп участвовал в разработке турецкой конституции 1924 г., сформулировав положения о свободе совести и лаицизме (секуляризм, светскость), выступал за синтез национальных традиций и достижений европейской цивилизации.

Турецкий теоретик культуры И. Кафесоглу считает, что турецкое и европейское общества имеют ярко выраженные различия в социальном, моральном, религиозно-философском смысле, и отмечает, что «современная турецкая молодежь находится под сильным влиянием западной культуры, в частности гуманистических идей Запада, и совершенно оторвана от родной почвы, от традиций своих отцов», лишена необходимой восприимчивости в вопросах, касающихся национальных интересов [3, с. 335]. «Тлетворное» иностранное влияние на Турцию отмечает известный турецкий прозаик К. Тахир, имея в виду в первую очередь американское «проникновение» в Турцию после Второй мировой войны. Писатель идеализирует средневековую Турцию и в качестве одной из причин отсталости своей страны называет забвение национальных традиций. Понятно, что процесс вестерниза- ции, как правило, протекает не просто [4, c. 451]. Турция, в которой западные ценности с переменным успехом внедряются уже два столетия, не стала страной на западный лад, хотя, возможно, в разное время руководители страны и хотели этого.

В отличие от вестернистов, почвенники (традиционалисты) борются за замкнутость обществ стран Востока, сохранение культурных традиций, защиту их от внешнего влияния и, естественно, отрицают взаимодействие и взаимовлияние западной и восточной цивилизаций. Идеологи консервативного турецкого национализма, выступая в защиту традиционных культурных ценностей и против проникновения в страну западной культуры и идеологии, препятствуют приобщению народа к прогрессивным идеям, стремясь оторвать турецкий народ от культурных общечеловеческих ценностей, их творческого освоения. Искусствовед Ф.Б. Берке отмечает несовместимость культуры мусульманского Востока, в том числе турецкой, с культурой Запада, поскольку в основе первой лежит ислам, а в основе второй - христианство. Ф.Б. Берке заявляет, что приобщение турок к западной культуре невозможно, ибо подлинное приобщение к ней требует проникновения к истокам этой культуры, то есть в христианскую религию, что совершенно неприемлемо: «Религия, не вскормленная искусством, не могла бы занять в человеческой душе нужное место» [8, с. 192]. Подобные мысли выдвигает в своих публикациях С. Эрдирен, утверждая, что современный турецкий художник должен способствовать своим искусством возрождению полузабытых, исконно религиозных понятий [8, с. 192].

Итак, западники считали, что принципы ислама по своей сути противоречат нормам современной цивилизации и не могут к ней адаптироваться, некоторые из них даже призывали отказаться от этих принципов и быстрее воспринять материальные и духовные достижения Европы. Традиционалисты же предлагали отказаться от европейских достижений совсем во имя сохранения и поддержания своих традиций. Зия Гёкалп не соглашался ни с первыми, ни со вторыми. Он отстаивал возможность совместимости этих двух столь разнородных начал - западной и восточной цивилизаций. Несовместимым с со- 
временным государством Зия Гёкалп считал сохранение теократии.

Младотурецкие лидеры во втором десятилетии XX в. пытались воплотить в жизнь некоторые идеи Зии Гёкалпа, направленные против элементов теократии в государственном управлении. В частности, шейх-уль-ислам был введен в состав кабинета министров, шариатские суды были отделены от ведомств шейх-уль-ислама и подчинены Министерству юстиции, медресе были переданы Министерству народного образования, администрация вакфов оказалась подотчетной одному из членов кабинета министров.

Проблему вестернизации Турции и взаимовлияния культур Востока и Запада пытался решить первый президент Турецкой Республики Мустафа Кемаль-паша (Ататюрк). Интерпретируя наиболее актуальные идеи Зии Гёкалпа, Мустафа Кемаль выделил основополагающие направления политической жизни Турции, получившие отражение в программе Народно-республиканской партии (далее НРП) и ставшие ее принципами, такие как национализм (независимость), этатизм (активное участие государства в экономической жизни общества), лаицизм (секуляризм), революционность, республиканизм, народность. Эти шесть принципов Мустафа Кемаль вывел как некий особый путь Турции, прибавив к ним полную независимость государства, национальный подъем и модернизацию. Как отмечает исследователь Э.Х. Кылычбейли, эти шесть базовых принципов, вместе с принципами современного общества образующие модель республики М.К. Ататюрка, являют собой образец целостной модели развития также и для других стран Евразии [10, с. 279].

Принцип революционности подразумевал преобразования в разных сферах жизнедеятельности государства (государственного устройства, судопроизводства, культуры, быта). Республиканизм и национализм были признанием европейского опыта строительства национального государства, а народность - дань общинным идеалам исламского мира. Таким образом, в модели «нация - государство», созданной Мустафой Кемалем, были объединены принципы республиканизм, национализм и светскость.

Важным элементом новой идеологии стал лаицизм, который ставил своей целью исключить возможность захвата политической власти исламистскими силами. М.К. Ататюрк считал, что главной причиной отсталости Османской империи, ее поражения в Первой мировой войне была ее приверженность ко многим изжившим себя исламским догмам. Первый президент избрал путь постепенного избавления турецкой нации от гегемонии арабо-персидской культуры с целью развития собственного национального самосознания. Одним из направлений развития турецкой культуры он думал сделать развитие отношений с тюркскими народами Средней Азии.

Процесс строительства Турецкой Республики был ориентирован на ценности Запада, однако консервативная часть общества стала сопротивляться модернизационным процессам, инициированным первым президентом государства. Поэтому Мустафа Кемальпаша осуществлял преобразования постепенно. Конституция Турецкой Республики 1924 г. даже не предусматривала разделения властей, законодательная и исполнительная ветви были сосредоточены в меджлисе, не обеспечивалась независимость судебной системы, не предусматривался такой важный элемент демократии, как многопартийность, сохранялся в качестве государственной религии ислам.

По мере поляризации идейных позиций различных групп и слоев в лагере кемалистов и за его пределами, кристаллизовалась и идеология кемализма, отчетливо выступали ее основные принципы: родина, нация, республика, общественные права. Кемализм иногда понимается шире - не только как идеологическая система, но и как путь развития Турции в период ее преобразования из полуколониальной страны с феодально-клерикальным строем в независимое буржуазно-национальное государство. Трактовке принципов и основ кемализма посвятили свои работы турецкие исследователи Р. Пекер, Ш. Айкут, Ш. Айдемир, Н. Беркес, Ф. Наджи, С. Кили, И. Эюбоглу, М. Тунчай, А. Ильхан, Э. Конгар и др. Например, исследователь С. Кили «кемалистскую революцию» рассматривает сквозь призму ее модификации как некой интернациональной модели для развивающихся стран $[14 ; 15]$.

В 1920-1930-х гг. в Турции были проведены реформы. Мустафа Кемаль летом 1925 г. 
отправился в путешествие по стране, во время которого проводил агитацию за отказ от пережитков прошлого. Сенсацию произвел уже тот факт, что, остановившись в г. Кастамону, первый турецкий президент вышел из автомобиля со шляпой в руке. Шляпа была в старой Турции символом «гяура», «неверного». Мусульманина, надевшего европейскую шляпу, могли закидать камнями. Не менее кощунственным считалось появление с непокрытой головой. М.К. Ататюрк личным примером подал сигнал к борьбе против этих предрассудков. В своих беседах во время путешествия он указывал на необходимость отказаться от ношения фески и от всякого рода специфических восточных костюмов. Немедленно по всей Турции стала вводиться европейская одежда, в том числе и головные уборы. На манифестациях в честь Кемаля-паши публично сжигались фески. Кое-где полиция принудительно снимала фески с граждан. Вскоре турецкое правительство опубликовало декрет, которым запрещалось ношение фески, все государственные служащие обязывались носить шляпу, быть в присутственных местах с непокрытой головой, приветствовать друг друга по-европейски и т. д. За несколько дней торговцы распродали весь запас шляп и фуражек. Мастерские не успевали выполнять заказы. Два вагона шляп предприимчивые стамбульские коммерсанты получили из-за границы.

Историческая обстановка в Турции в период национально-освободительной борьбы 1918-1923 гг. сложилась так, что верхушка мусульманского духовенства во главе с халифом оказалась на стороне Антанты и таким образом потеряла возможность прямо влиять на политическую организацию вновь созданной республики, анатолийское же духовенство в значительной части влилось в ряды национал-патриотов. В результате консерваторам и исламистам удалось лишь притормозить процесс вестернизации, но остановить его они не смогли. Более того, кемалистам удалось ликвидировать халифат, зафиксировать в конституции принцип лаицизма и создать светскую республику, что ослабило влияние ислама в стране. Лиацизм был важным средством модернизации страны. В странах мусульманского Востока сложился тип культуры, в кото- ром господствовало религиозное мировосприятие, сильно отличавшееся от культурной концепции Запада. В немалой степени именно религиозное мировосприятие в конечном итоге привело к культурной изоляции и застою мусульманских народов. Мусульмане не имели другой классической культуры, кроме той, которая была сформирована исламом [9].

В 1925 г. Великое национальное собрание Турции (далее - ВНСТ) приняло закон о закрытии религиозных обителей, тюрбе, в которых покоились почитавшиеся священными останки султанов и шейхов. Были запрещены мистические ордена - тарикаты, в том числе наиболее одиозные - накшбанди, мевлеви, тиджани, влиятельные религиозные секты, а их собственность перешла государству. Эти монашеские ордена прежде играли огромную роль во внутренней жизни Турции. Их было множество. Пользуясь фанатизмом отсталого населения, шейхи орденов приобрели большое влияние, особенно в отдаленных районах, где центральная власть не имела достаточной опоры. В некоторых местах приказания шейхов выполнялись скорее и точнее, чем распоряжения правительства. Эти ордена выступали против политики лаицизма, ревностно добивались восстановления арабского языка в религиозном культе, ратовали за введение преподавания религиозных предметов в школах. Исламские школы были закрыты, а в государственных школах прекращено преподавание ислама. Большое прогрессивное значение имело введение в действие в 1926 г. Гражданского кодекса, построенного по европейскому образцу, который заменил шариат. Он, в частности, предусматривал ликвидацию многоженства и введение гражданских браков. Тюремное заключение ожидало тех, кто эксплуатировал религиозные чувства верующих, наказанию подлежали религиозные деятели, использующие ислам в политических целях. А в 1928 г. из турецкой конституции было исключено положение о том, что государственной религией Турции является ислам. Страна стала светской республикой. Церковь была окончательно отделена от государства. Однако борьба кемалистов против влияния духовенства отнюдь не являлась борьбой против самой религии. Кемалисты сами старательно подчеркивали это отличие. Само духовенство все 
больше становилось «кемалистским». Коран перевели с арабского на турецкий язык. Традиционный азан зазвучал с минаретов не на языке пророка - арабском, а на турецком языке. Наконец, в 1934 г. правительство запретило служителям всех культов ношение культовой одежды вне церковной службы. Тем самым шейхи и дервиши теряли в глазах населения свою исключительность и превращались в обычных граждан. Ходжи и муллы появились на улицах турецких городов в обычных пиджаках. Даже священный мусульманский день отдыха кемалисты в интересах торговых отношений с зарубежными странами перенесли с пятницы на воскресенье.

Значительные перемены произошли в области просвещения. Прежние религиозные школы меньше всего способствовали поднятию уровня образования. Софты (учащиеся медресе) заботились лишь о том, чтобы избавиться от воинской повинности. Ввиду этого многие софты делались «вечными студентами», а, проучившись 20-30 лет, выходили из школы полуграмотными. После ликвидации медресе и закрытия других религиозных школ в Турции было введено исключительно светское образование.

Не менее важным событием стала реформа алфавита. Арабский алфавит, полученный турками вместе с исламом, чрезвычайно затруднял развитие грамотности в стране. Несвойственный турецкому языку, он не имеет достаточного количества гласных букв, неудобен при письме, усложняет ведение торговых записей (буквы идут справа налево, а цифры - слева направо). Предложения о переходе на латинизированный алфавит делались в Турции неоднократно. Долгое время мусульманское духовенство противилось реформе. Старый алфавит, недоступный подавляющему большинству населения, позволял духовенству сохранять в своих руках монополию грамотности. Однако, сломив сопротивление клерикалов в других вопросах, кемалисты сумели осуществить и эту реформу. Решающее значение имело выступление Мустафы Кемаля в пользу латинского алфавита. 1928 г. был ознаменован важным актом вестернизации: 1 ноября 1928 г. ВНСТ приняло Закон о реформе алфавита, и уже в 1929 г. арабский шрифт в турецком языке был изменен на ла- тинский, это облегчало распространение грамотности среди населения. Арабский язык постепенно вытеснялся из религиозного и общественного обихода.

Сеть учебных заведений увеличилась, открылись новые высшие школы. После реформы алфавита кемалисты повели борьбу за «тюркизацию» турецкого языка - за очищение его от слов арабского и персидского происхождения. Одновременно была поставлена задача создания национальных изящных искусств - живописи, музыки, скульптуры и т. д.

Мустафа Кемаль считал, что реформы должны вывести турецкий народ из состояния невежества, поднять грамотность населения, европеизировать турецкое общество. Турция быстро меняла свое лицо. В школах было введено совместное обучение полов. Турчанки сняли чадру. Прогрессивной мерой кемалистов было стремление уравнять женщину в правах с мужчинами, предоставить ей право на образование, занятие должностей, избирать и быть избранной в органы государственной власти. Среди женщин появились адвокаты, врачи, судьи. В 1930 г. женщинам было предоставлено право выборов в муниципалитеты, а в 1934 г. - в парламент (появление на турецком политическом олимпе Тансу Чиллер в 1990-е гг. - закономерный результат политики эмансипации женщины) [7].

В 1934 г. ВНСТ приняло закон о введении фамилий (прежде турки имели лишь имена). Мустафа Кемаль получил фамилию Ататюрк - «отец турок». Закон 1934 г. упразднил титулы и старые формы обращения: паша, бей, эфенди.

Несомненно, преобразования в области государственного устройства, культуры, быта имели прогрессивное значение. Они способствовали национальному укреплению Турции и ее переходу от феодальных к буржуазным формам общественной жизни.

В сфере экономики Зия Гёкалп первостепенным считал национальную ориентацию. Он не соглашался с мнением ряда экономистов о том, будто экономика наднациональна, считая, что каждая страна развивает национальную экономику. М.К. Ататюрк тоже считал, что экономика должна быть подчинена национальным интересам: «Мы охотно воспользуемся услугами иностранного капитала, при ус- 
ловии, если концессионеры будут подчиняться нашим нынешним и будущим законам и уважать принятые нами в этом отношении национальные принципы» [1, с. 283]. Историческая заслуга Мустафы Кемаля заключается также и в том, что он одним из первых среди политических деятелей стран Востока понял особую роль государства в решении проблемы преодоления экономической отсталости путем ускорения темпов хозяйственного роста. Но если в 1920-е гг. Мустафа Кемаль пытался превратить Турцию в подобие Европы, в «страну богатых» с помощью турецких предпринимателей, то с начала 1930-х гг. полностью выявилась неспособность турецкого предпринимателя вывести из тупика хозяйство страны. В этой связи М.К. Ататюрк и его единомышленники взяли на вооружение идеи протекционизма и активного вмешательства государства в экономическую жизнь - этатизм (смена принципов хозяйствования была официально закреплена в принятой в 1931 г. программе Народно-республиканской партии) [11, c. 63]. «Степень экономической развитости нации, - писал Зия Гёкалп, - пропорциональна степени разделения труда. <...> В стране с отсталой экономикой наука, искусство, философия, даже мораль и религия никогда не могут отдельно достичь высших проявлений» (цит. по: [13, с. 46-47]). Зия Гёкалп видел теснейшую взаимосвязь и взаимозависимость всех сфер жизни общества, необходимость комплексного подхода к реформам. Сложность для реформаторов состояла в том, чтобы найти свой путь модернизации общества. Поиск такого пути составлял различные аспекты философии Зии Гёкалпа.

Pезультаты. Можно констатировать, что основополагающие принципы кемализма были сформулированы М.К. Ататюрком и реализованы не сразу, а по этапам.

На первом этапе формирования идеологии кемализма - этапе национально-освободительной борьбы (1918-1923 гг.) - были выдвинуты такие принципы, как национализм, народность, республиканизм. К тому периоду относится определение внешнеполитического курса кемалистов.

Второй этап развития идеологии кемализма (1924-1932 гг.) охватывает такие периоды, как ликвидация султаната и провозглашение республики, избрание М. Кемаля президентом, осуществление реформ, претворяющих в жизнь лаицизм, этатизм, революционность.

Третий этап реализации идей Кемаляпаши (1932-1940-е гг.) совпадает с периодом монопольного нахождения у власти Народнореспубликанской партии. На этом этапе теоретическое обоснование принципов кемализма дает программа НРП.

Четвертый этап эволюции кемализма приходится на конец 1930-х - 1950-е годы. Исходная дата периода - смерть М.К. Ататюрка (1938 г.), конечная - приход в 1950 г. к власти в Турции Демократической партии. В этот период происходит активизация реакционных сил в стране, атакам подвергаются такие принципы кемализма, как этатизм, лаицизм.

Пятый этап характеризуется новыми осмыслением и трактовкой основных принципов кемализма, как и всего идейного наследия М.К. Ататюрка, после государственного переворота 1960 г. и по настоящее время. Возникает новая трактовка принципов кемализма. Исследователь Э.Ю. Гасанова отмечает, что на этом этапе кемализм претерпел некую метаморфозу. Оставаясь по сути националистической идеологией, кемализм в своей нереализованной части используется широкими слоями общественности, требующими применить неокемализм, под которым подразумевается борьба против ущемления суверенитета Турции, экспансии в страну иностранного капитала [6, с. 172-173].

М. Кемаль отделил тюркизм от пантюркизма, заимствовав у Зии Гёкалпа такие элементы, как понимание нации, народничество, этатизм. Национальная идея нашла свое выражение в форме национального суверенитета. Таким образом, национализм стал доминирующей идеологией Турции. В политике секуляризации М.К. Ататюрк пошел дальше предложений тюркистов и вестернистов, утвердив принципы светскости и республиканизма. Однако внесение кемалистами изменений в официальную идеологию не решило проблемы идейно-политического характера страны, распространения новых идеологических установок. 1980-е гг. отмечены ростом влияния оппозиционной исламистской партии Рефах. Характер и содержание идеологической борь- 
бы в Турции в 1990-е гг. показывают, что кемализм теряет свою власть. В данном контексте примечателен приход к власти в Турции в 2002 г. ныне правящей исламистской Партии справедливости и развития (далее ПСР). Все более популярным в Турции становится мнение доктора Ибрагима Калына о том, что хотя политический курс, проводимый в Турции правящей ПСР, зачастую кажется продиктованным идеологическими факторами, такими как исламизм и неоосоманизм, но не менее решающие факторы турецкой политики, в частности внешней, в действительности базируются на более практичных предпосылках, таких как экономические потребности Турции, ее исторические связи с соседями, деликатное геополитическое местоположение [5, с. 116].

Как пишет исследователь П.А. Варбанец, если удастся примирить ислам и современность, доказать, что центристский ислам возможен, то, вероятно, может появиться новая модель государственного устройства для исламского мира [2, с. 174]. Нет ислама, как нет и христианства, вне конкретного историко-культурного этапа развития не только конкретного общества, но и народа. Консерватизм и радикализм, традиционализм и модернизм на турецкой почве, по сути, тупиковые пути. Соотношение между традицией и реформой всегда обусловлено реалиями конкретного общества в конкретную эпоху. Необходимо знать собственные традиции, историю развития специфических тюркских социальных, конфессиональных институтов для того, чтобы суметь приспособить их к новым жизненным реалиям и оценить, в какой мере они могли бы взаимодействовать с элементами современной западной цивилизации.

Можно констатировать, что М.К. Ататюрк старался европеизировать государство и увести турецкое общество от османского прошлого. В течение XX в. Турция предприняла беспрецедентные попытки импортировать западную культуру, она находится на пути к Европе, но при этом никогда не теряла свою собственную идентичность, и именно это стремление становится все более актуальным на сегодняшний день, в том числе и из-за постоянных отказов западных стран включить Турцию в Европейский союз.

\section{СПИСОК ЛИТЕРАТУРЫ}

1. Ататюрк, К. Избранные речи и выступления / К. Ататюрк. - М. : Наука, 1966. - 428 c.

2. Варбанец, Р. А. К вопросу о зарождении и эволюции идеологии кемализма в Турции / Р. А. Варбанец // Турция в XX веке. - М. : Акад. гуманит. исслед., 2004. $-352 \mathrm{c.}$

3. Вартаньян, Э. Г. Культура Турции / Э. Г. Вартаньян. - Краснодар : Изд-во КубГУ, 2006. - 440 с.

4. Вартаньян, Э. Г. Сельджуки - османы - турки: становление и развитие культуры / Э. Г. Вартаньян. - Краснодар : Изд-во КубГУ, 2007. - 607 с.

5. Гайдаева, Ю. Ю. Турция: идеология и политика будущего. Нео-оттоманизм или кемализм / Ю. Ю. Гайдаева // Известия Саратовского университета. Новая серия. Серия: Социология. Политология. - 2014. - Т. 14, № 2. - С. 116-120.

6. Гасанова, Э. Ю. Об идеологии национально-освободительного движения в Турции и роли Кемаля Ататюрка в ее развитии / Э. Ю. Гасанова // Турция. Истории и современность. - М. : Наука, 1988. - C. 165-176.

7. Евроченков, А. Тансу Чиллер / А. Евроченков // Азия и Африка сегодня. - 1993. - № 10. - С. 36-37.

8. Заманова, Э. Э. Националистическая интерпретация культурного наследия и отношение к духовным ценностям Запада в современной Турции / Э. Э. Заманова // Турция. История и современность. - М. : Наука, 1988. - С. 189-195.

9. Измайлов, Р. И. Кемализм и модернизационные процессы в Турции в 20-30-е годы XX века / Р. И. Измайлов. - Электрон. текстовые дан. - Режим доступа: http://www.idmedina.ru/ books/ materials/turkology/1/turk_izmailov.htm (дата обращения: 19.08.2016). - Загл. с экрана.

10. Кылычбейли, Э. Х. Евразийская геополитика: Турция и Россия (старые понятия, новые подходы) / Э. Х. Кылычбейли // Турция в ХХ веке. М. : Акад. гуманит. исслед., 2004. - С. 274-296.

11. Моисеев, П. П. Концепция Кемаля Ататюрка по проблемам развития национальной экономики / П. П. Моисеев // Etudes Balkaniges. - Sofia : [s. n.], 1985. - № 1. - C. 58-71.

12. Фадеева, И. Л. От империи к национальному государству. Идеи турецкого социолога Зии Гёк Алпа в ретроспективе XX века / И. Л. Фадеева. М. : Вост. лит. РАН, 2001. $-214 \mathrm{c}$.

13. Фадеева, И. Традиционализм и модернизация / И. Фадеева // Азия и Африка сегодня. - 1994. № 2. - C. 42-47.

14. Kili, S. Kemalizm / S. Kili. - Istanbul : School of Business Administration and Economics, Robert College, 1969. $-239 \mathrm{p}$.

15. Kili, S. Kemalism in Contemporary Turkey / S. Kili // International Political Science Review. - 
1980. - P. 381-404. -(Revue Internationale De Science Politique; vol. 1, no. 3).

16. Ziya Gökalp. Turkish Nationalism and Western Civilization: Selected Essays of Ziya Gokalp / Ziya Gökalp ; transl. and ed. with an introduction by N. Berces. - First ed. - N. Y. :Allen \& Unwin, 1959. - 167 p.

\section{REFERENCES}

1. Atatyurk K. Izbrannye rechi $i$ vystupleniya [Selected Speeches and Performances]. Moscow, Nauka Publ., 1966. 428 p.

2. Varbanets R.A. K voprosu o zarozhdenii i evolyutsii ideologii kemalizma v Turtsii [To the Issue of the Origin and Evolution of the Kemalism Ideology in Turkey]. Turtsiya $v X X$ veke [Turkey in the $20^{\text {th }}$ Century]. Moscow, Akademiya gumanitarnykh issledovaniy, 2004. 352 p.

3. Vartanyan E.G. Kultura Turtsii [Culture of Turkey]. Krasnodar, Izd-vo KubGU, 2006. 440 p.

4. Vartanyan E.G. Seldzuki - osmany - turki: stanovlenie $i$ razvitie kulturi [Seljuks-OttomansTurkish: Formation and Cultural Development]. Krasnodar, Izd-vo KubGU, 2007. 607 p.

5. Gaydaeva Yu.Yu. Turtsiya: ideologiya i politika budushchego. Neo-ottomanizm ili kemalizm [Turkey: Ideology and Policy of the Future. NeoOttomanizm or Kemalism]. Izvestiya Saratovskogo universiteta. Novaya seriya. Seriya: Sotsiologiya. Politologiya [Izvestiya of Saratov University. New Series. Series: Sociology. Politology], 2014, vol. 14, no. 2,pp. 116-120.

6. Gasanova E.Yu. Ob ideologii natsionalnoosvoboditelnogo dvizheniya v Turtsii i roli Kemalya Atatyurka $v$ ee razvitii [About the Ideology of the National Liberation Movement in Turkey and Kemal Atatyurk's Role in Its Development]. Turtsiya. Istoriya i sovremennost [Turkey. History and Modernity]. Moscow, Nauka Publ., 1988, pp. 165-176.

7. Evrochenkov A. Tansu Chiller. Aziya i Afrika segodnya [Asia and Africa Today], 1993, no. 10, pp. 36-37.
8. Zamanova E.E. Natsionalisticheskaya interpretatsiya kulturnogo naslediya $\mathrm{i}$ otnoshenie $\mathrm{k}$ dukhovnym tsennostyam Zapada v sovremennoy Turtsii [Nationalist Interpretation of Cultural Heritage and the Attitude Towards Cultural Wealth of the West in Modern Turkey]. Turtsiya. Istoriy a i sovremennost [Turkey. History and Modernity]. Moscow, Nauka Publ., 1988, pp. 189-195.

9. Izmaylov R.I. Kemalizm i modernizatsionnye protsessy v Turtsii v 20-30-e gody XXveka. [Kemalism and Modernization Processes in Turkey in the 20-30s of the $20^{\text {th }}$ Century]. URL: http://www. idmedina. ru/ books/ materials/ turkology/1/turk_izmailov.htm (accessed 19 August 2016).

10. Kylychbeyli E.Kh. Evraziyskaya geopolitika: Turtsiya i Rossiya (starye ponyatiya, novye podkhody) [Euroasian Geopolitics: Turkey and Russia (Old Concepts, New Approaches)]. Turtsiya v XX veke [Turkey in the $20^{\text {th }}$ Century]. Moscow, Akademiya gumanitarnykh issledovaniy, 2004, pp. 274-296.

11. Moiseev P.P. Kontseptsiya Kemalya Atatyurka po problemam razvitiya natsionalnoy ekonomiki [Kemal Atatyurk's Concept on Problems of Developing the National Economy]. Etudes Balkaniges. Sofia, 1985, no. 1 ,pp. 58-71.

12. Fadeeva I.L. Ot imperii $k$ natsionalnomu gosudarstvu. Idei turetskogo sotsiologa Zii Gek Alpa $v$ retrospektive $X X$ veka [From the Empire to the National State. The Ideas of Turkish Sociologist Ziya Gyok Alpa in the $20^{\text {th }}$ Century Retrospective]. Moscow, Vostochnaya literatura RAN, 2001.214 p.

13. Fadeeva I.L. Traditsionalizm i modernizatsiya [Traditionalism and Modernization]. Aziya i Afrika segodnya [Asia and Africa Today], 1994, no. 2, pp. 42-47.

14. Kili S. Kemalizm [Kemalism]. Istanbul, School of Business Administration and Economics, Robert College, 1969. 239 p.

15. Kili S. Kemalism in Contemporary Turkey. International Political Science Review, 1980, pp. 381-404. (Revue Internationale De Science Politique, vol. 1, no. 3).

16. Ziya G. Turkish Nationalism and Western Civilization. Selected Essays of Ziya Gokalp. New York, Allen \& Unwin, 1959. 167 p.

\section{Information about the Author}

Egnara G. Vartanyan, Doctor of Sciences (History), Professor, Department of World History and International Relations, Kuban State Universaty, Stavropolskaya St., 149, 350040 Krasnodar, Russian Federation, vartaneg@yandex.ru, https://orcid.org/0000-0001-5030-8941

\section{Информация об авторе}

Эгнара Гайковна Вартаньян, доктор исторических наук, профессор кафедры всеобщей истории и международных отношений, Кубанский государственный университет, ул. Ставропольская, 149, 350040 г. Краснодар, Российская Федерация, vartaneg@yandex.ru, https://orcid.org/0000-0001-5030-8941 